\title{
autêntica
}

ARTIGOS

\section{FORMAÇÃO DE PROFESSORES DE EDUCAÇÃO INFANTIL EM PORTUGAL E NO BRASIL: UMA CONVERSA COM MARIA DO CÉU ROLDÃO ${ }^{1}$}

Marineide de Oliveira Gomes

RESUMO: O presente texto trata de reflexões sobre a formação de professores em Portugal e no Brasil. Teve como fonte uma entrevista realizada pela autora com a pesquisadora portuguesa Maria do Céu Roldão. O objetivo do trabalho foi aprofundar a reflexão sobre a temática da formação do professor no ensino superior no campo da pesquisa educacional, com larga produção nos dois países.

PALAVRAS-CHAVE: Formação de professores; pesquisa educacional, Educação Superior

\section{ABSTRACT}

This paper reflects on the teachers training in Portugal and Brazil, with the specific source an interview conducted by the author of this article with the Portuguese researcher Maria do Céu Roldão. The objective of this work was to deepen the reflection on the topic of the teacher training for professional practice in higher education in the field of educational research, with extensive production in both countries.

KEYWORDS: Teacher training; Educational Research; Higher Education.

\footnotetext{
1 Entrevista realizada pela professora doutora Marineide de Oliveira Gomes (Unifesp,campus Guarulhos) com a professora doutora Maria do Céu Roldão (UCP,campus Lisboa). O material aqui veiculado faz parte do corpus de pesquisa de pós-doutoramento da entrevistadora, realizada em 2014 na UCP, sob supervisão do professordoutor João Manuel Formosinho, intitulada A formação de professores de educação infantil em Portugal e no Brasil: aproximações e distanciamentos, e contou com bolsa de estudos do Programa de Estágio Sênior no Exterior da CAPES.
} 


\section{APRESENTAÇÃO}

As reflexões expostas neste texto sobre a formação de professores em Portugal e no Brasil é fruto de uma conversa (em forma de entrevista realizada em janeiro de 2014) com a professora Maria do Céu Roldão, que nos recebeu na Universidade Católica Portuguesa (UCP), campus Lisboa. Nossa intenção foi aprofundar o tema da formação de professores em geral e, em particular, de professores de educação infantil, na imbricação entre teoria e prática e da função das avaliações externas dos cursos que formam professores em nível superior. A entrevista ocorreu no âmbito dos estudos de pós-doutoramento em Educação da autora na UCP, onde a professora doutora Maria do Céu Roldão, que participou como colaboradora e sujeito da pesquisa, é docente. Considerando sua produção no campo da formação de professores e, sobretudo, sua participação nas Comissões de Avaliadores Externos de cursos dessa área e sua importante experiência com processos de revisão curricular de cursos de formação de professores do primeiro ciclo em Portugal (ensino fundamental, no Brasil) e de educadores de infância naquele país, temos a perspectiva de que esse material que divulgamos redundará e possibilitará uma reflexão sobre o tema para a área.

Nos tempos atuais de reflexão sobre a manutenção das conquistas do direito à educação e a qualidade dos cursos que formam professores em nosso país, a experiência de Portugal relatada pela entrevistada nos auxilia a compreender alguns fatores que condicionam a qualidade da formação docente.

Apresentamos a entrevista em três blocos. O primeiro trata das políticas, do direito à educação da infância e da formação de professores; o segundo trata da organização dos cursos de formação de professores; e, por fim, no último bloco a entrevista se dirige aos temas da avaliação e da qualidade dos cursos de formação.

\section{O DIRETO À EDUCAÇÃO DA INFÂNCIA: POLÍTICAS DE FORMAÇÃO DE PROFESSORES - BRASIL/PORTUGAL}

\section{O DIREITO À EDUCAÇÃO DA INFÂNCIA E A FORMAÇÃO DE PROFESSORES}

E - Para contextualizar o tema da nossa entrevista e as relações entre Brasil e Portugal no campo da educação infantil: no Brasil, demos um grande salto na Constituição Federal de 1988 inaugurando o conceito de educação infantil no campo da educação, que envolve o trabalho educacional em creches (para crianças de 0 a 3 anos). Essas estavam, até então, sob a responsabilidade da área da Assistência Social, sendo que tiveram um tempo, posteriormente, para se adequar à área da educação. As pré-escolas (para crianças na faixa etária de 4 a 5 anos) já estavam no campo da educação e sob a responsabilidade dos municípios. Prioritariamente, os municípios no Brasil são responsáveis pela educação infantil e agora também pelos anos iniciais do ensino fundamental (que seria o $1^{\circ}$ ciclo do ensino básico em Portugal).

MCR- Mas essa é uma reivindicação aqui também, porque o atendimento de 0 a 3 anos está fora, formalmente...

E -Na sua opinião, como se explica que em Portugal o trabalho institucional com crianças de 0 a 3 anos não esteja sob a responsabilidade do Ministério da Educação?

MCR - Isso é o reflexo da história. Dos 3 aos 6 anos, em princípio, o atendimento aqui também passou por esse processo, era pela Assistência Social, pelas IPSS [Instituições Públicas de Solidariedade Social], e evoluiu para uma oferta por parte do Ministério da Educação, cuja rede coexiste com as IPSS. 


\section{autêntica}

E -Uma construção social que (a exemplo do que ocorreu historicamente no mundo) se relaciona com a história da mulher, do mundo do trabalho, das transformações sociais. Mas a resposta política, de garantia de política pública, de garantia de direitos, parece-me que ainda está distante.

MCR - Essas múltiplas visões ainda existem, e dos 3 a 6 anos, mesmo nos cursos de formação de professores, ainda se confrontam muitas visões dos fundamentos, pois as concepções estão arraigadas na ideia do assistencial, do desenvolvimental, da "preparação para", havendo muitas controvérsias[...].

E -Sabemos também que não é o lugar que muda as concepções e nem a política pública em si, mas sobretudo as práticas dos docentes. Nesse sentido, como você avalia a organização dos cursos de formação de educadores de infância hoje para dar respostas ao direito à educação das crianças pequenas, tão advogado nas últimas décadas no mundo?

MCR - É justamente para responder à nova necessidade das licenciaturas, por um lado de ter cursos mais exigentes, (...) existiu, em 2000, o Inafop [Instituto Nacional de Formação de Professores], que é o precursor das políticas de acreditação dos cursos, não de avaliação deles. Muitos acadêmicos do país que estavam ligados a essa área participaram naquela altura desse processo. O Inafop tinha um mandato para acreditar os cursos, avaliar as suas pertinências, não o desenvolvimento e o funcionamento. Porém, cada vez que muda a política aqui, muda-se tudo, deita-se abaixo o que existia.

E -No Brasil nós chamamos isso de "administração zigue-zag".

MCR - Só no Brasil mesmo para se falar uma coisa tão bem! É isso mesmo: zigue-zag! Depois que o Inafop foi extinto, quando foi lançado esse processo de acreditação, as Instituições de Ensino Superior (IES) já estavam se preparando para a reorganização dos cursos, visando responder à essa acreditação. Na Escola Superior de Educação (ESE) de Santarém, onde eu fiz referência, fizemos um processo de reformulação do curso e há inclusive investigação produzida sobre essa experiência. Procuramos transformar a lógica dos cursos de formação de professores de educação de infância e de professores do $1^{\circ}$ ciclo no sentido de responder mais a um perfil de licenciatura e profissionalizante, em que as competências profissionais fossem o ponto de referência e a articulação dos componentes curriculares do curso fossem reconcebidas em outra lógica. Eu coordenei esse projeto e tinha a responsabilidade de estruturar, com a equipe, as dimensões da prática. Olhando agora o pós-Processo de Bolonha, isso foi muito interessante. Houve também reformulações em outras instituições, com iniciativas diferentes. Nós reconstruímos o curso na lógica de que o eixo estruturante da formação era a prática profissional, e todo o resto - as dimensões científicas e as outras dimensões pedagógicas, didáticas - tinham que girar em torno do eixo da prática profissional, o que foi um avanço importante do ponto de vista da visão de educação, o que implicava em uma reconfiguração, sobretudo das dimensões organizacionais das instituições formadoras. Exemplo: ter um corpo docente mais fixado em cada curso e não na lógica dos segmentos, de dar uma aulinha aqui e ali... Naquela altura, eu participava do Conselho Científico e me empenhei para que isso fosse apropriado pela instituição. Entendíamos que a prática profissional deveria ser assumida pelo curso e pelo conjunto dos docentes. No primeiro ano do curso os alunos faziam as observações e os registros de práticas profissionais duas vezes por ano no terreno profissional. No segundo ano, tinha uma pequena intervenção, e no terceiro e no quarto havia o estágio. Tinha uma equipe de professores e, contra uma tradição anterior em que os professores da prática eram menos qualificados, revertemos isso. Haviam outros professores bem-qualificados que se responsabilizavam pela prática profissional. Criamos situações de entrosamento entre os professores de modo que, quando os alunos iam para a prática profissional (nas escolas do terreno), os professores de outras áreas tinham 
interrupção das suas aulas, que depois eram compensadas. Esses professores das diferentes disciplinas acompanhavam os professores responsáveis pelas práticas no terreno profissional para as aulas nas escolas, e tínhamos coisas bem interessantes: alguns professores ligados às artes passaram a desenvolver um olhar diferente para as práticas dos estudantes e falavam: "Isso é interessante. Eu não tinha ideia de como era uma aula de jardim de infância" "e "Vou mudar minhas aulas". Isso combinava no último ano com um tempo intensivo de práticas - também chamado de estágio. Nós, os professores das práticas, estávamos todas as semanas nas escolas com tempo maior ainda do que as horas que nos eram destinadas pelo curso. Havia um triângulo formativo nesse processo: o aluno, a escola cooperante e a instituição formadora. A Comissão de Avaliação dos cursos tinha como critério verificar como era feita essa formação no terreno. Foi um dos primeiros cursos em que houve reprovação no último ano, e isso era indicador de como se pensava que o estágio era fácil. Tinha-se uma ideia de que não havia exigência para a atuação com a prática pedagógica. De maneira geral, se fazia um dossiê e isso bastava. Existia uma tradição de benevolência, e os professores da instituição iam pouco às escolas. Eu costumo indicar as reprovações como "melhoria" nesse contexto, e os alunos participavam da avaliação que envolvia a reflexão sobre como eles trabalhavam, como ensinavam as crianças; criávamos perfis de desempenho com eles, o que exigia um tempo maior dedicado à instituição. De início, houve resistências e isso regrediu depois, passado alguns anos. Temos o caso de dois alunos que foram reprovados, não desistiram, continuaram e se tornaram, depois, excelentes professores. No quarto ano do curso os alunos tinham quase só a prática profissional: eram 26 semanas no terreno mais os Seminários de Acompanhamento da Prática e de Investigação. Eles produziam uma pequena monografia investigativa sobre a prática, que era apreciada por um júri de conclusão de curso.

\section{O DIREITO À EDUCAÇÃO DAS CRIANÇAS PEQUENAS EM PORTUGAL E AS FORÇAS POLÍTICAS QUE ENGENDRAM AS POLÍTICAS EDUCACIONAIS}

E - Parece haver um senso comum no campo da formação de professores de crianças pequenas de que basta saber cuidar das crianças, porque são pequenas, e garantir que elas fiquem bem. Voltando à questão que fiz anteriormente, como você avalia que, do ponto de vista político, um país que já deu respostas sociais a tantas demandas da sociedade como Portugal negligencie essa etapa tão importante da vida das crianças como o trabalho educacional do 0 a 3 anos? Como se explica isso considerando a reconfiguração social, econômica e política das últimas décadas com a inserção cada vez maior da mulher no mundo do trabalho? As forças que poderiam se mobilizar para essa mudança, os sindicatos, o que fazem nesse sentido? O que justificaria que, passados quarenta anos de políticas mais voltadas para o campo social em Portugal, essa situação se mantenha?

MCR - Uma pergunta muito pertinente que eu não sei responder. É, de fato, uma perplexidade muito grande. Sobre os sindicatos, em Portugal, nos sindicatos da educação, dos professores, observa-se uma forte partidarização, e eles estão um pouco desacreditados pela opinião pública. Fiz parte das Comissões para a criação, ainda no tempo da Ditadura, dos primeiros sindicatos de professores. Em Portugal há duas grandes Federações Nacionais de sindicatos. Inicialmente estavam sob a égide do Partido Comunista (PC) e eram considerados sindicatos fortes. No período de 1970 e 1980 surgiram outros sindicatos e houve uma grande luta política: o PC e a Intersindical queriam manter a unicidade sindical com um único sindicato para cada grupo profissional, havendo a emergência de outros sindicatos que vieram da parte de outros partidos. Acho que no Brasil a vivência sindical tem uma grande marca de esquerda, como em Portugal, mas tem uma inserção, uma implantação no viver das populações maior, mais diversa, mais genuína. Me parece que o sindicato está mais vinculado às bases. Isso é só uma impressão, não vivi, não trabalhei no Brasil. Entre nós, houve a emergência dos sindicatos (me lembro do dia que se reuniu pela primeira vez o sindicato dos professores 


\section{autêntica}

e, naquela altura, o Rui Grácio, um dos grandes teóricos da educação em Portugal, que era perseguidíssimo na Ditadura, eu o encontrei lá e ele estava a chorar pela existência de uma voz a nos defender). Depois o poder político cresceu e houve muita manipulação, gerando algum descrédito. Temos hoje dois núcleos de sindicatos: um da linha do Partido Comunista, outro de linha socialista e social democrata, que se afirmam, em boa parte, pela oposição um ao outro. A lógica partidária está na representação pública, portanto os sindicatos, mesmo o sindicato dos professores do $1^{\circ}$ ciclo, têm muito menos representação e voz do que os outros. E a máquina sindical funciona numa lógica contabilista, os sindicatos tornaram-se conservadores e focam-se na defesa da corporação; do que seria a luta sindical, o aspecto cívico em si, isso vemos pouco. Os professores de educação de infância têm uma representação absolutamente mínima, pois não representam votos, falando o português cru. Em geral, os sindicatos de professores em Portugal são forças políticas a serviço dos partidos políticos e perderam força no campo profissional.

E - Nesse caso estou me referindo aos sindicatos generalizadamente, não só aos sindicatos dos professores. Mesmo se não considerarmos o direito da criança, ter como bandeira o papel da mulher na sociedade tem como consequência a necessidade de um lugar para deixar seus filhos com educação e segurança. Muitos sindicatos no Brasil encamparam essa reivindicação, assim como a melhoria dos salários, isso desde a década de 1970.Por outro lado, sabemos que a creche é um equipamento caro e tem havido algumas respostas dos municípios, como auxílio-creche para os trabalhadores pagarem as escolas privadas. Como isso ocorre em Portugal?

MCR - Temos dois tipos de problemas: um é a cobertura do atendimento em creche. Outro problema é o de assumir a creche como educação ou como assistência.

E - Hoje em Portugal esse nível de educação está sob a responsabilidade do Ministério do Trabalho e Segurança Social. Embora o discurso seja de que é educacional.

MCR - Me parece que as classes mais favorecidas resolvem o problema colocando seus filhos nas instituições privadas, e a perplexidade que temos é a de que os sindicatos não lutem por isso. Há, por parte das famílias, dispositivos não formais, como as avós que ficam com os netos, alguém da família que cuida. Nesse momento é menos eficaz, pois as avós estão trabalhando e, em muitos casos, sustentam os filhos desempregados. Trata-se de um fenômeno que não sei explicar. Por outro lado, somos uma sociedade de forte tradição familiar. Do ponto de vista da matriz cultural, a sociedade portuguesa é muito marcada por uma visão conservadora de família na sua essência, e isso, me parece, tem relação com menor reconhecimento político, sobretudo para as mulheres, da garantia desse direito. As mulheres urbanas, as mais pobres, são muito marcadas por lógicas familiares tradicionais em que o homem tem primazia, e nisso você tem toda razão, de fato é um fenômeno intrigante.

E - No final das contas você avalia que isso se aproximaria de uma política do "pobre para o pobre"?

MCR - Isso merece ser mais aprofundado. Não conheço pesquisas sobre o porquê desses processos. No entorno de Lisboa, que tem muita migração, funciona um esquema familiar, há persistência de uma forma atávica nesse nível. Temos políticas claramente economicistas, e o problema se agrava há dez anos, mas a sua pergunta me questiona o antes. Eu própria, há quarenta anos, era uma mãe separada com dois filhos pequenos, e como se resolvia o problema de ter onde deixá-los para trabalhar? Eu levava-os para as reuniões, e a escola que eu trabalhava no ensino básico como professora de História organizou uma creche. Nós todas 
nos cotizamos, a diretora obteve um subsídio qualquer, e há isso por toda a parte, soluções intermediárias daqueles que não estão nem na franja dos mais pobres nem na dos mais ricos. Há um silêncio político que é estranho. Pode ter essa razão da tradição, não sei...

E - Um conformismo que tem subjacente uma certa concepção de criança. Talvez se a concepção de criança como sujeito de direitos fosse mais visível para a sociedade e, sobretudo, para as famílias, quem sabe a situação fosse outra.

MCR - É uma zona de investigação pobre também. Há um silêncio político sobre isso, mas olhando aqui são pequenas bolsas de estudos, com pouca visibilidade.

\subsection{AS POLÍTICAS EDUCACIONAIS, O PROCESSO DE BOLONHA EM PORTUGAL (E NA EUROPA) E A FORMAÇÃO DE PROFESSORES}

E - E hoje, pós-Processo de Bolonha, qual é a sua avaliação sobre a forma como se organizam os cursos que formam professores de educação de infância?

MCR - O Processo de Bolonha traz em seus princípios um grande ganho: a marcação do $1^{\circ}$ (graduação) e do $2^{\circ}$ ciclo de formação (mestrado profissionalizante), com a exigência do $2^{\circ}$ ciclo para a profissão docente, na esteira do que para nós já tinha sido uma conquista anterior. Mas houve, naquela altura, uma resistência, pois no contexto de Portugal havia o risco de recuo, e alguns setores pretendiam retroceder para que os professores só tivessem o $1^{\circ}$ ciclo. Foi uma batalha ganha naquela altura. Outro ponto que destaco nas orientações do Processo de Bolonha e que é escassamente apropriado é a centralidade no trabalho autônomo do aluno, reduzindo, em teoria, a dimensão apresentativa do trabalho do professor. O principal para mim é como o curso deve se repensar, qual o significado de cada disciplina com relação ao trabalho autônomo do aluno. Esse princípio está longe de ser concretizado, de se centrar mais na aprendizagem do que no ensino, o que implica a reorganização dos processos de trabalho. E isso não está acontecendo, o que houve foi uma adaptação aritmética. Antes se tinha "tantos tempos letivos" e agora há "tantos créditos". Do meu ponto de vista as escolas de formação de professores continuam a funcionar no modelo anterior, e as queixas do Processo de Bolonha são que se tem agora menos tempo para a formação prática, para a investigação, ou para isso e aquilo - e é verdade -, mas não houve na organização dos cursos e no ensino e no trabalho com os alunos uma nova configuração. Querem introduzir o formato de Bolonha da organização dos cursos em uma estrutura que continua a funcionar pré-Bolonha. As grandes dificuldades resultam do fato de que a estrutura pós-Bolonha implicava e implicará uma reconfiguração organizativa dos cursos que, na minha opinião, está longe de ocorrer, mas precisamos de investigação para podermos afirmar isso de fato.

E -Quase que como uma ideia mágica de que os decretos e as leis mudam as práticas, mas o "habitus" de Bourdieu está lá presente.

MCR - Pois é, o habitus e as representações que nós próprios temos e, ainda, as condições de trabalho. A experiência anterior, antes de Bolonha, já tinha uma lógica de organização curricular e de estrutura transformativa diferente da soma das partes e da sequencialização. Temos modelos integrados de currículos em que a prática existe desde o $1^{\circ}$ ano, mas está lá isolada, não contagia, não impregna, não modifica o modo como o curso é concebido, e a tentativa de transformação do curso de Santarém que eu citei era de mudar essa lógica. E havia muitas dificuldades, pois tínhamos três destinatários, e agora é a mesma coisa: os alunos, os 


\section{autêntica}

professores cooperantes e a instituição formadora, como campos que uma transformação desse tipo tem que mexer. Os alunos, em princípio, resistiam e depois saiam muito bem-preparados porque houve uma diferenciação que eles se apropriaram. Os professores que os recebiam nas escolas (os professores cooperantes) resistiram a princípio, pois não estavam acostumados com esse trabalho, que envolvia acompanhamento, investigação, e depois a maioria aderiu, havendo bom progresso. Para os docentes da ESE que estiveram envolvidos, houve uma adesão importante, mas para alguns era incômodo mexer com a disciplina mais as tarefas de análise e de observação que foram acrescidas. Tivemos por volta de $50 \%$ de adesão, e observamos que a maior resistência partiu da própria organização, das direções dos cursos. Achava-se um abuso seis professores de prática terem três horas semanais para ir à escola de ensino básico. Acompanhar a prática profissional era considerado um desperdício, e nós sabíamos, por outro lado, que três horas de trabalho não era suficiente. Na realidade íamos muito mais, ficávamos dez horas por semana nas escolas cooperantes, além dos cursos que ministrávamos... O olhar do ponto de vista administrativo era outro. Havia também os "ciúmes" dos outros cursos - de educação não formal -, pois eles tinham estágios, e a princípio foi olhado como benefício extraordinário ter três horas a mais no horário, que eles depois também passaram a desejar. As lógicas da organização eram muito resistentes. Depois que viram o que era, não queriam mais, pois a lógica da própria organização era difícil garantir que um núcleo de professores se mantivesse no curso. Mexe-se no edifício, mexe-se em uma lógica instalada, por essa razão não vale fazer um decreto, não adianta, porque as transformações são construídas, e o mesmo aconteceu com o Processo de Bolonha. Tive a oportunidade de ver isso em outras instituições: na Universidade de Aveiro e na Universidade do Minho vi os processos, e o que me parece é que a instauração do Processo de Bolonha não correspondeu a uma reconfiguração organizacional e nem pedagógica, podendo haver honrosas exceções. Desse ponto de vista, o Processo de Bolonha aparentemente agravou as dificuldades, o que pode se traduzir em algumas perdas. A reconfiguração da organização, isso só se constrói por dentro. Com Bolonha a grande queixa é sobre o tempo curto para a prática pedagógica e para a investigação, e se soma a isso os cortes de verbas e os problemas atuais. Seria preciso lideranças muito conscientes para fazer isso, e ainda temos as políticas recentes em Portugal, com os cortes sistemáticos de financiamento, impossibilitando formar equipes, a falta de tempo, a dificuldade para contratação de professores etc. Naquela experiência que citei, trabalhávamos muito em pares ou trios de docentes da ESE de Santarém no acompanhamento da prática profissional, assim como os alunos iam ao terreno sempre em duplas. Nós planejávamos juntos e íamos juntos nas escolas do terreno. Do ponto de vista dos cortes financeiros, essas zonas têm sido decrescentes, pois não há condições objetivas de manutenção dessa estrutura. Hoje o professor que tem a responsabilidade da prática profissional tem muitos alunos para acompanhar, por razão de economia de recursos. Antes tínhamos no máximo seis alunos para supervisionar e colaborávamos uns com os outros.

E -Parece que nas políticas (em geral) sempre se quer fazer mais com menos.

MCR - Fazer mais com menos. É um segundo milagre. O primeiro é a crença nas mudanças por decreto (que não é verdade) e o segundo é esse, de que é possível fazer mais com menos. Não é possível. Antes estávamos num bom caminho. Mesmo o Processo de Bolonha poderia ter sido um fator para melhorar isso. Houve um caminho muito revigorante de construção da profissão docente que está hoje a se colocar em causa, a ser deixado de lado. O Inafop, as Comissões de Avaliação e a introdução do Processo de Bolonha foram caminhos afirmativos da profissionalidade docente. No caso dos educadores de infância isso foi muito forte, por ser um subgrupo dentro da profissão docente, que tem uma história mais deficitária. Esse impulso no final da década de 1990 e no início do século XXI foi de reforço e de modernização. Com esses dispositivos, a acreditação, que era prévia ao funcionamento dos cursos, foi um dos passos importantes, pois obrigou as IES a repensarem como estruturar os cursos, a ter um projeto que fizesse sentido, com 
critérios de referência e planejamento estratégico de como o curso funcionaria. Isso obrigou as escolas a se repensarem, distinguindo a acreditação da avaliação.

E -De certa maneira, a dimensão da gestão interna se escancara quando há processos de avaliação externa.

MCR - A avaliação obriga a olhar para dentro. Sou favorável sempre aos dispositivos de avaliação como fundamentais para os processos de melhoria, mas vejo resistências à avaliação como consequência própria de uma cultura de países que viveram períodos longos de Ditadura, isso criou marcas, mas já se passaram outros quarenta anos...

E -Parece que na área da educação é tudo muito difícil nesse processo de construção (que é sempre coletivo) e, sem continuidade, corre-se o risco de não se sair do lugar.

MCR - A avaliação é sempre olhada, independentemente de ter havido erros. Já escrevi sobre isso no capítulo de conclusão de um livro²resultante de projeto que participei de investigação na Universidade de Aveiro sobre avaliação de desempenho de professores. Existiu uma guerra contra a avaliação de professores e se perdeu a memória desse processo. Nesses estudos citados na investigação, os porquês apresentados pelos sujeitos para a rejeição são sempre iguais, e o que não nos perguntamos é o que explica essa violência que, de maneira geral, se atribui apenas aos modos, aos erros de formulação das políticas e de como foram implementados os processos malfeitos, a falta de gradualidade, entre outros. E é verdade, mas do lado das escolas há uma resistência profunda, quase atávica, contra as avaliações, e parece ser uma marca transversa Isobre a avaliação, se argumentando que isso se deve ao passado. Eu me lembro da repressão dos processos de avaliação formais no tempo da Ditadura em Portugal em que, por exemplo, professores não eram contratados porque tinham ideias políticas contrárias ao governo, ou professoras por viverem juntos com seus namorados, não sendo casadas. Isso "avaliava" negativamente os professores e parece que gerou a ideia de avaliação como ameaça, permanecendo essa memória no inconsciente coletivo.

E - Parece quase um fantasma.

MCR - É verdade. E o problema, me parece, é não ser possível melhorar os cursos de formação sem fazer uma avaliação que os escancare internamente, não para punir, mas para melhorar e para não ficar sem financiamento ao nível das políticas públicas. Faz-se necessário haver dispositivos de avaliação acompanhados de dispositivos de sustentação e dar razão à ideia de não querer que avaliações sejam feitas (conforme citado acima). Utilizada cientificamente, a avaliação é um instrumento desejável. Pode haver dissimulação por parte da maioria das pessoas que está interessada em não tornar público essas constatações.

E-Algo como uma roupa que não está feita e se impõe o "modelo tamanho único", que não serve nem para uma pessoa anoréxica nem para pessoas obesas, ou seja, não atende à diversidade, à realidade.

MCR - Fazemos avaliações (e pesquisas) para nos autoconsolar, nos mestrados, nos doutoramentos etc. Como o presidente do Inafop, professor Paiva Campos, o primeiro diretor do Instituto de Educação na Universidade Católica Portuguesa dizia "Pelo amor de Deus, não me venham com mais investigações que estão a dizer a nós próprios as mesmas coisas sem se avaliar o porquê dessas reincidências". Tem reforma 


\section{autêntica}

atrás de reforma, um modo de fazer que está impresso na matriz dessas instituições, e enquanto isso não for confrontado, tenho a impressão de que as mudanças estarão longe de ocorrer.

E - Parece que sempre que se fala em avaliação há reações, como o que você chamou de fantasma que está no inconsciente coletivo.

MCR - Exato. Nas políticas tem (que ser) cruzado a dimensão reguladora (para melhorar) com a certificação para tirar consequências. Essa é uma questão central na avaliação, se essas dimensões devem estar juntas ou separadas, o impacto das pessoas[os avaliadores externos] na avaliação de desempenho com bolsa de avaliadores externos - isso esvaziou a angústia dos professores, mas a avaliação pelos pares para mim era uma das maneiras essenciais de se organizar as avaliações. Essa avaliação agora, com pessoas de fora, funciona caricaturando, só vão para certificar, observam duas aulas e são poucos os que fazem isso ainda, sem função avaliativa real. O avaliador externo, por sua vez, não acompanha aulas e não cria constrangimentos. Tirou-se o incômodo colocando as almofadas [paleativos] e não se vai a lugar nenhum. Uma avaliação, de fato, não se faz sem supervisão, essa é uma zona de susceptibilidades e um estratagema político. Um avaliador externo que vem ver uma aula e não sabe o que se faz no ano todo... são formas de avaliar, formas de os próprios sistemas políticos rodearem as dificuldades por ser a avaliação uma zona de dificuldade) fica facilitada, fica menor pela não exibição do confronto. Penso ser importante fazer o confronto com as regras do confronto, separando a dimensão regulativa, do desenvolvimento profissional, da função certificativa, de carreira -teria que se conseguir um casamento entre essas funções da avaliação.

\section{FORMAÇÃO DE PROFESSORES: O CURSO E SUA ORIENTAÇÃO FORMATIVA}

\subsection{ORIENTAÇÕES FORMATIVAS E A ORGANIZAÇÃO DOS CURSOS DE FORMAÇÃO DE PROFESSORES EM PORTUGAL E NO BRASIL}

E - Gostaria que você falasse sobre os isomorfismos de processos formativos. Como você vê essa coerência entre as diretrizes de formação de professores em relação às orientações para o trabalho com as crianças pequenas e a forma de organização dos cursos?

MCR -Um campo de muitas contradições. Há vários autores da área do currículo que falam de currículo de processos. Acho que a prática letiva docente dos cursos de formação desse nível e de outros contradiz em larga medida com o que se propõe para os alunos junto às crianças: defende-se partilha entre as crianças, centrar-se nas experiências anteriores, desenvolver a autonomia, o trabalho de pesquisa, e isso é proposto frequentemente nos currículos dos cursos de formação de professores, mas servidos de dispositivos de ensino superior, que continuam muito tradicionais. Ter a ilusão de que se ensina alguém a ensinar de forma ativa, reflexiva e analítica por meio de processos transmissivos significa que se mantém a matriz tradicional. Na minha avaliação, a universidade é o expoente mais elevado de uma cultura organizacional e profissional arcaica, e a academia tem um poder social acrescido. Podemos não gostar, mas é um fato e isso formata as representações. É a conversa de São Tomás de Aquino: "olhas o que digo e não o que faço." A lógica do Processo de Bolonha poderia ter tratado disso, do aluno poder investigar, ter outras práticas, e o professor ser um gestor desse processo. Isso peca por incoerência porque, para que os cursos de formação de professores sejam coerentes, consistentes com essa concepção de prática, é fundamental que a instituição ofereça, exemplifique com essas lógicas de formação e que opere dessa forma. Nessa perspectiva, a presença da prática pode ser feita de muitas maneiras, de contato com as práticas por meio de seminários, por exemplo, consoante as diferentes circunstâncias. Sou avessa a criar bons princípios prévios, porque acho 
que a formação é processual e em contexto, com critérios para a formação com exposição e imersão em processos homólogos, o que pode e precisa ser feito de muitas maneiras. A prescrição normativa seria em forma de princípios, situações desejáveis e, depois, haveria um processo deavaliação: o que foi feito e como foi feito -não vejo vantagens em se estabelecer modelos muito rígidos. Há uma distância entre as normativas e o que acontece de fato, devendo haver concordância entre o que se deseja fazer com o estudante, qual formação será privilegiada e o que se vem a estabelecer.

E - Com relação aos cursos públicos e privados de formação de professores em Portugal, como você avalia a diferença entre eles, ou quais seriam as diferenças mais significativas?

MCR - Tem diferença, porém do ponto de vista dos requisitos legais, eles são os mesmos. A diferença está no fato de que as instituições privadas, muitas, tendem a ser menos exigentes do ponto de vista da organização dos cursos e, sobretudo, das dimensões da prática, condensando cursos, com ofertas de formação em tempo reduzido. Uma outra diferença apontada pelos alunos é que os cursos (das instituições privadas) tendem a ser muito inflacionistas nas notas das avaliações finais. Os critérios de rigor das universidades públicas em Braga eram um dos problemas, pois com os critérios de excelência nas públicas se produzia alunos e professores muitos bons. Acontece que eles se queixavam de serem preteridos no trabalho, no caso do concurso nacional; e é claro que o poder da nota era o poder da nota, eles eram melhor preparados, mas não tinham tão boas notas. Essa é uma imagem grosseira porque há instituições privadas que não fazem isso e que, portanto, não cabem na generalização. No caso das instituições privadas menos reconhecidas socialmente há, em muitos casos, essa ideia de maior facilitação, de tempos de formação mais compactados, que fazem pacotes de fim de semana, sem formação prática, com uma lógica mais comercial, mas a avaliação das instituições privadas obedece ao mesmo rigor das instituições públicas. Não tenho dados recentes, mas a Agência de Avaliação e Acreditação do Ensino Superior (a A3ES) tem produzido alguma depuração desses casos extremos. Em 2000, e agora também, a A3ES obrigou as instituições privadas a terem critérios mais rigorosos, e várias instituições fecharam (as mais escandalosas do ponto de vista do despreparo para funcionar). Elas podem continuar a funcionar, mas sem o diploma reconhecido, o que resultou em melhoria significativa na qualidade dos cursos de formação em geral. A principal diferença é que eles (da A3ES) organizam a captação dos alunos (nas instituições públicas hoje isso também pode acontecer, sendo que atualmente há menor procura). No Conselho Científico, naquela altura, eu insisti várias vezes que na entrada da carreira profissional deveria haver uma seleção dos candidatos pelo perfil de competências, mas há controvérsias. Eu tentei criar nos critérios de acesso (que tendem a ser massificados) a possibilidade de ter entrevistas com os candidatos e isso nunca foi aceito, pelo argumento de que, diante das dificuldades, eles poderiam fugir para outro lado.

E - Algo como aferir a capacidade vocacional para a profissão?

MCR - Seria preciso um Estado muito inteligente, uma lógica mais reguladora, porque as pessoas vão sendo formadas numa lógica muito automática. Seria importante ter uma lógica sem reduzir os critérios pela competição dos públicos. Nesse caso eu veria com bons olhos uma função reguladora do Estado. Isso devia ser valorizado, pois a avaliação teria que demonstrar que os critérios produziriam melhoria da qualidade dos cursos, com consequências que cobrissem algum déficit.

\section{AS TENSÕES NA ORGANIZAÇÃO DOS CURSOS DE FORMAÇÃO DE PROFESSORES}

E - Olhando hoje para o modo como os cursos de formação de professores se estruturam, como você considera que eles deveriam ser organizados para garantir o direito à educação das crianças pequenas? 


\section{autêntica}

MCR - Para pensar sobre isso precisamos nos pôr ao lado de quem tem o direito à educação - as crianças. O sujeito da educação, nesse caso, o aluno, (criança, jovem ou adulto) é sempre o objeto principal para a organização dos cursos de formação de professores. No caso da infância, dos meninos e das meninas, é o direito maior, se se pode dizer na verdade que dele depende tudo o que vem depois. Eles são descurados na maioria dos sistemas, as instituições formadoras dão menor peso político a essa fase da vida e é aqui que se joga - do lado desses sujeitos - tudo na vida deles. A educação de infância e o ensino básico deveriam ter os maiores níveis de investimento.

E - Mas observamos o contrário nas políticas públicas educacionais em geral.

MCR - Há coisas que estão a acontecer que eu não julgava que alcançaria ver, mas isso há de ser superado. Do ponto de vista do direito, na minha opinião, a educação de infância é o direito maior, no qual se projetam mais as desigualdades sociais, d partida (sic), na educação de infância e no $1^{\circ}$ ciclo da educação básica. A qualidade dos serviços que as crianças têm acesso é, nesses níveis, absolutamente determinante na forma como elas vão continuar os estudos, ter mobilidade social a partir de seus pontos de partida - sendo então os mais frágeis - decorrente das fragilidades sociais. As populações que têm menos possibilidades de acesso à educação são portadoras de maior déficit econômico e sociocultural e se não forem acolhidas no início, não serão em momento nenhum. Para mim essa é a ideia mais importante: os sistemas deveriam fazer um investimento acrescido na formação de professores para esse nível e na qualidade desses níveis educacionais. Embora tenhamos hoje a escolaridade básica obrigatória em Portugal, a verdade é que os dispositivos "automáticos" de seleção social continuam a operar e, portanto, continuamos a perder crianças e adolescentes, crianças que já não estão mais no sistema escolar pelo abandono e pela exclusão ou, se estão, como estão a ser tratados, ensinados e o que se faz com eles? Estatisticamente há mortalidades. Sabendo que durante muito tempo essas perdas vão ocorrer, o tempo privilegiado que as escolas têm com as crianças é o da infância, sendo determinante a educação do 0 a 3 anos. Parece que houve um relativo avanço no atendimento de crianças dos3 aos 5e até os 10 anos. Em Portugal, em geral, saem menos crianças da escola, mas não temos registros desse outro abandono, o abandono interno, da não aprendizagem por muitas crianças. Comparando com 10, -15 anos passados, aumentou muitíssimo o acesso à educação de infância. É um tempo com as crianças para agir sobre elas, e os profissionais que vão atuar têm que ser bem preparados. E eu diria que a noção de que é um direito do cidadão, a criança deveria ser particularmente acarinhada, apoiada. Os professores mais importantes são esses, do ponto de vista da construção do direito real à educação. Por outro lado, é uma fase da criança em que o professor tem (como dizemos em Portugal) a faca e o queijo na mão, porque aos 17, 18 anos os alunos já estão com as competências básicas quase prontas, já interiorizaram as representações dos códigos culturais, e o tempo do professor é outro. Eles já estão no secundário, e no caso deum percurso que não foi bem-sucedido há pouco a se fazer, pois há um campo mais limitado. O professor da infância tema matéria-prima, o que é um trabalho mais difícil. Teve um episódio de uma aluna em uma aula sobre o Desenvolvimento Profissional dos Professores, em que eu estava falando das categorias do Shulman, e ela, com os olhos muito arregalados, dizia: "Professora, mas é preciso isso tudo para ser professora? Eu julgava que era um curso fácil, por isso vim para cá", em que eu respondi: "Se pensava assim é melhor ir embora, pois os professores da infância precisam disso tudo." Precisa saber tratar as crianças de diferentes culturas, saber como entender as culturas de pertença, por exemplo, como a cultura oral condiciona ou formata o modo neurológico de aprender, de funcionar, e nós, professores, sabemos pouco sobre isso. Os estudos da Neurociências e das Ciências da Cognição não estão nos cursos de formação de professores, e eu, pelo menos, não sei nada. Leio o António Damásio, faço algumas incursões literárias, mas é preciso saber como o cérebro funciona. Nesses níveis iniciais com as crianças precisamos saber das bases que sustentam tudo, a aprendizagem, o desenvolvimento. Essa ideia, também presente nas universidades, de que a profissão docente é fácil, precisa ser desconstruída. 


\subsection{A IMBRICAÇÃO ENTRE TEORIA E PRÁTICA E A IMPORTÂNCIA DA FORMAÇÃO EM CONTEXTO NOS CURSOS DE FORMAÇÃO DE PROFESSORES}

E - Sobre a organização dos cursos que formam professores de educação de infância visando a garantia dos direitos das crianças, quais os principais problemas que você avalia que existam nos cursos de formação de professores, no que diz respeito, sobretudo, à prática supervisionada?

MCR -Minha impressão é que [a organização dos cursos] recuou, que o investimento acrescido nas supervisões mais sustentadas, com investimento e envolvimento, agora alargadamente com o Processo de Bolonha - não como resultado direto de Bolonha, mas na lógica organizativa que Bolonha imprimiu -, não foram apropriadas (as mudanças), sobretudo nesse contexto de redução de recursos e olhares absolutamente produtivistas, em que as lógicas da educação em geral e da formação de professores estão sendo abocanhadas.

E - Você vê importância na ideia de que a prática supervisionada seja feita em diferentes contextos formativos, de que os estudantes possam experienciar diferentes abordagens de formação e de condições de produção da profissão docente?

MCR - A partir daquela experiência que citei, de Santarém, entendo que devam haver princípios gerais e soluções contextuais. Para mim, as instituições deveriam ter autonomia sobre como fazer e responderem por essa condição. Porque digo isso? Um princípio é o que se fazia antes da nossa reformulação do curso na ESE de Santarém, de nós alocarmos os estagiários nas escolas, porque sabíamos que eram boas escolas e que haviam boas práticas de professores, professores esses que foram nossos alunos e que estavam espalhados, diluídos em várias escolas. Enquanto esse critério era predominante, os alunos ficavam longe e diminuia o poder de nossa supervisão e, consequentemente, a formação com o professor cooperante[o professor da escola que acolhe o estagiário]. Lembra-se do triângulo: estudante, professor da universidade e professor cooperante? Isso, ao meu ver, não era muito eficaz no que se refere aos meios, pois os contextos eram menos favorecidos, mas o critério era a qualidade do professor. Depois, em uma outra configuração, a opção era valorizar esse triângulo, garantindo o trabalho do professor da ESE com a escola cooperante e um trabalho com o professor e com o estagiário. Nessa lógica foi preciso deixar o critério do bom professor e das práticas e fazer a opção por um critério geográfico com escolas que tivessem um contexto organizativo interessante, onde existiam professores bons e menos bons, envolvendo protocolos diretamente com essas escolas por três ou quatro anos, tendo uma efetiva parceria da escola com a instituição universitária. Isso permitiu reduzir custos, pois não tínhamos que atravessar regiões distantes e, além disso, poderíamos construir culturas de supervisão nessas escolas e trabalhar com outras pessoas. Resultou em uma solução política interessante, saindo dali bons professores formados. Portanto eu diria que havia uma terceira possibilidade que estava presente nas antigas Escolas Normais, que era uma escola anexa, as Escolas de Aplicação, muito contestadas na época, como um retrato desvirtuado da realidade. Não seria o caso de abandonar essa ideia, mas (ela seria) uma alternativa intermediária com as escolas parceiras permanentes, criando uma tradição de colaboração com a instituição universitária. Dessa forma considero que três ou quatro princípios são importantes: 1) parceria com a instituição e impacto na organização da escola; 2) qualidade dos professores cooperantes; 3 ) impacto da qualidade e colaboração permanente entre a instituição que forma professores e a escola básica. Mais do que o contato com contextos muito diferenciados (não acho isso absolutamente essencial), considero que isso possa ser feito em diferentes etapas do curso e de diferentes formas. No estágio é difícil combinar essa diversidade da prática profissional. No sistema antigo tínhamos 26 semanas na mesma escola. Depois mudamos para outra forma, inspirada na experiência da Universidade de Aveiro, talvez na Universidade do Minho também tivesse algo parecido. Ao invés de 26 semanas na 
escola, o estudante ficava metade do tempo em uma escola e depois a outra metade, em outra, com uma passagem de testemunho, um momento de transferência, um relatório ou um seminário público. Tentávamos encontrar uma diversidade nos meios sociais das escolas. A prática supervisionada é um tempo de reflexão conjunta, regular, que envolve trabalho prolongado e um envolvimento cada vez mais informado do professor cooperante, por ser esse professor um informante privilegiado daquela cultura escolar. Tivemos o caso de uma professora - ela não era uma má professora -, e ela dizia às estudantes/estagiárias e, supostamente, devia julgar que eu fazia um discurso um tanto impróprio: "Quando a 'senhora' (referindo-se à professora supervisora da Universidade) cá vier, vocês fazem assim com ela... Depois vocês vão fazer como eu faço", julgando, dessa forma, que os estudantes ficariam caladinhos, mas eles nos contavam. E os estudantes nos perguntavam o que fazer. Então estavam representadas ali as duas culturas. Também se tem que contrariar isso, se consideramos a opção de que bons professores, que são portadores de uma cultura local, em geral não fazem muita investigação, assim o supervisor deve fazer o cruzamento dos três vetores. O professor da instituição formadora precisa estar muito envolvido, mas o investimento da instituição varia, havendo resistências culturais e, por vezes, a dificuldade de pessoal e dinheiro para as alocações piora isso. Naquela experiência da Universidade do Minho, os professores conseguiam ter uma presença marcante nas escolas, mas não conseguiam ir, pois a universidade não garantia as condições estruturais. Isso perpetua uma cultura profissional da escola básica que se distancia de uma teoria mais informada ou reflexiva.

\section{AVALIAÇÃO E QUALIDADE DA FORMAÇÃO}

\section{A AVALIAÇÃo EXTERNA DE CURSOS DE GRADUAÇÃo EM PORTUGAL}

E -Considerando a sua experiência com cursos que formam professores e sobretudo com avaliação externa dos cursos de graduação de formação de professores em Portugal, gostaria, por gentileza, que você nos relatasse a história e a estrutura de avaliação desses cursos em Portugal.

MCR - Minha colaboração em processos de avaliação ocorreu nas primeiras avaliações externas que foram lançadas em Portugal, no ano 2000, a primeira, para cursos que formam professores do $1^{\circ}$ ciclo e educadores de infância. Depois, em 2005, participei de uma Comissão idêntica, já no $2^{\circ}$ ciclo de avaliação. Foram essas duas Comissões que abriram caminho para a avaliação dos cursos de graduação em Portugal. Eram Comissões mandatadas pelo Ministério da Educação como órgãos autônomos, com subcomissões para todos os cursos. Esse processo mais tarde foi modificado e organizado com base no Processo de Bolonha. A fase atual busca atender às diretrizes europeias por meio da A3Es, mas há outros organismos do mesmo tipo na Europa.

E - Por quanto tempo então você esteve como avaliadora de cursos de graduação?

MCR -A primeira Comissão de Avaliação funcionou em 2001/2002 e, depois, a outra, ao longo de 2005 e 2006. Participei de ambas que tinham mandato específico envolvendo o trabalho, a nomeação, a prestação de contas, a elaboração de relatórios, a divulgação e o contraditório, e não estava ainda institucionalizada uma estrutura que funcionasse de forma permanente. O que era permanente era a Comissão Nacional de Avaliação do Ensino Superior (CNAES), que criava as subcomissões necessárias.

E-Parece que a diferença ou o que distingue a A3ES da forma como as avaliações anteriores eram feitas é a entrada de Portugal no Espaço Europeu de Educação Superior pelo Processo de Bolonha com as exigências europeias para a organização dos cursos. Isso faz sentido? 
MCR - De fato. Foram exigências padronizadas pelo Processo de Bolonha. A segunda avaliação correspondia a uma avaliação geral dos cursos, o que foi resultante de uma decisão nacional de que os professores do $1^{\circ}$ ciclo e os educadores de infância passariam a ter licenciatura, a mesma exigência requerida para os professores das áreas específicas: Português, Matemática, etc. (o que hoje é o $2^{\circ}$ ciclo de formação, em nível de mestrado). Até essa mudança, a formação dos professores do $1^{\circ}$ ciclo do ensino básico era de bacharelado, um curso superior, digamos, de menor grau, mas houve uma transformação importante (não me lembro exatamente a data) quando se passou a exigir um grau maior, tal como os professores do secundário, o grau de licenciatura (que hoje, pós-Processo de Bolonha, é o $2^{\circ}$ ciclo, ou seja, o mestrado). Essa igualização dos professores do $1^{\circ}$ ciclo, um "upgrade" - ao mesmo nível dos outros -, foi importante na qualificação desses professores, pois antes eles eram vistos como professores de $2^{\text {a }}$ categoria, e em alguns países da Europa isso continua acontecendo, na perpsectiva de uma formação mais curta, sem diferenciação de níveis acadêmicos. Nas Escolas Superiores de Educação (ESE), que funcionam nos Institutos Politécnicos (IP) e em algumas universidades, os cursos se transformaram para garantir uma melhor formação dos professores, com trabalho final de curso, monografia e alguma investigação, o que representou uma exigência mais acadêmica do que em uma tradição anterior, mais prática, herdeira dos antigos cursos de Magistério, ou seja, das Escolas Normais. Isso só se modificou nas ESE após a reorganização do país com o 25 de abril (de 1974), primeiro como bacharelados e depois como licenciaturas, anterior ao Processo de Bolonha mas muito marcante, pois fez com que as escolas e as universidades olhassem para esses cursos com outra finalidade. O sistema, sendo dual, distingue o ensino dos IP do ensino das universidades, mas ambos oferecem o mesmo tipo de formação para professores do $1^{\circ}$ e do $2^{\circ}$ ciclos (até o $6^{\circ}$ ano de escolaridade elementar). $\mathrm{Na}$ formação de professores do $3^{\circ}$ ciclo do ensino básico (a partir do $7^{\circ}$ ano nas áreas específicas) e do secundário, a formação só é feita nas universidades. Para os cursos de formação de professores dos anos que antecedem $\circ 6^{\circ}$ anodo ensino básico, esses podem ser oferecidos pelas universidades ou pelas ESE, com os mesmos requisitos legais.

\subsection{A QUALIDADE DA FORMAÇÃO DE PROFESSORES EM PORTUGAL E NO BRASIL E A AUTONOMIA DAS AVALIAÇÕES EXTERNAS}

E - Na sua opinião, o que seria um curso de formação de professores de boa qualidade?

MCR - O ponto chave para mim é ter como referente a professora formar e olhá-lo como um profissional (uma das zonas importantes a estudar é a profissionalidade, o estatuto dos professores, ainda semiprofissional, dividido, instabilizado entre o funcionalismo e uma certa visão muito personalista da profissão), com competências interpessoais que não são centrais, com esvaziamento do saber e do como ensinar, tendo que desenvolver conhecimento, competências da área do técnico, do científico e do pedagógico. Os professores são um grupo social ainda muito fluido do ponto de vista da sua profissionalidade, que é uma construção social. O António Nóvoa trata disso muito bem, e a formação também alimenta essa visão pouco profissional. Os outros cursos deveriam ser mais trabalhados em suas finalidades para a construção da ideia de quem é o profissional, o que ele tem que saber, o que ele tem que dominar. A prática profissional deveria se situar como centro da formação e ser agregadora de outras áreas. Os profissionais da área da saúde têm vindo reforçar isso. Não nos passa pela cabeça uma formação do médico que não seja centrada na clínica, nos casos concretos e numa discussão conjunta. Teria que haver mais componentes relativos ao desempenho e ao conhecimento profissional. Esse foi tema de uma conferência minha na ANPEd no Brasil (em 1997), e que é olhado pelos próprios professores como antagônico, o chamado "duplo funil": a dimensão científica valorizada nos níveis mais elevados, sem cuidar do saber pedagógico, e nos níveis menos elevados, valorizando sobretudo a dimensão pedagógica e menos o conhecimento do conteúdo. Corresponde à ideia de que 


\section{autêntica}

que para o saber profissional, à medida que se avança, só é preciso o conhecimento científico, sem o saber pedagógico, o que significa uma aberração do ponto de vista da distinção do professor como profissional. As instituições formadoras devem ter um papel nisso e trabalhar com os contextos no terreno em que os professores se tornam professores e, depois, nessas escolas, pois as discrepâncias não são confrontadas com nada. A discussão da qualidade implica que na formação inicial se tenha um referencial claro das competências profissionais, com uma lógica do componente da prática profissional acrescido dos componentes dos conhecimentos que a informa, mas trabalhando em conjunto, repousando em uma organização curricular e pedagógica do curso, na fixação do corpo docente, no debate e na reflexão. Tudo isso versus uma cultura departamental em que cada um fica no seu canto, sem integração. Considero importante admitir formatos diferentes. Os padrões vão ao nível da organização e devem ter princípios, e depois a instituição vai mostrar como faz e em nome do que faz, o que pode variar dentro de parâmetros estabelecidos e de resultados alcançados. Faz-se necessário que as instituições sejam inteligentes na sua forma de fazer a implantação e que diferentes formatos sejam exercitados.

E - Para terminar, gostaria de saber sobre a avaliação dos cursos de formação de professores justificando com uma contextualização sobre a avaliação dos cursos de graduação feita no Brasil. Há um sistema nacional de avaliação centralizado no Ministério da Educação, o Sistema Nacional de Avaliação da Educação Superior (SINAES), em que fazem parte um Banco de Avaliadores (professores do ensino superior) recrutados pelo Ministério da Educação (que é responsável pelas avaliações, que envolvem um processo que compreende alimentação on-line da documentação da IES e visita in loco de duplas de avaliadores, que enviam os dados e um parecer para o Ministério da Educação com um relatório, sendo o parecer conclusivo de responsabilidade do próprio Ministério da Educação). Considerando esse contexto brasileiro, como você avalia o fato de que em Portugal a agência de avaliação dos cursos de graduação não seja centralizada no Ministério da Educação e sim independente do governo, com autonomia para exercer o seu trabalho?

MCR - Eu acredito que desde as primeiras iniciativas - o Inafop, a CNAES, a A3Es - a reação das universidades à primeira avaliação foi brutal; e essa avaliação era muito soft se comparada à avaliação atual, pois era muito aberta. Como já mencionei, houve uma guerra, e a resistência dos acadêmicos a serem avaliados era enorme. Houve um processo de ganho que se deveu em grande parte ao fato de que essas instituições eram órgãos independentes, portanto, não tutelados, e produziam todo aquele conhecimento. Para mim, a independência e a autonomia são critérios fundamentais. Considero um ganho serem instituições nacionais porque garantem uma certa aferição transversal, sendo importante também não haver subáreas com juízos diferenciados. Penso ser mais benéfico um órgão que possa ter uma voz do que a tendência de ficar a mercê e submetido a uma decisão ministerial. O princípio da isenção, a meu ver, é muito importante para se poder atuar com independência e autonomia, o que permite muitas vezes marcar uma posição das instituições de formação de professores junto à política. Na avaliação de desempenho de professores, fiz parte de um órgão autônomo e nomeado pelo Ministério da Educação, o Conselho Científico de Avaliação de Professores (CCAP), que tinha também várias representações e produzia recomendações e documentos orientadores, não tendo nada a ver com a tutela. Houve situações em que a tutela não gostou dos pareceres e recomendações. Uma vez criado o órgão, ele era autônomo. Isso é um fator fundamental também para a qualidade dos cursos e para sua avaliação credível. 


\section{CONSIDERAÇÕES FINAIS ALÉM-MAR}

A entrevista trouxe-nos um olhar acerca da formação de professores da educação de infância nas últimas décadas em Portugal, sobretudo com o advento do Processo de Bolonha, que estabeleceu diretrizes gerais para a formação em nível superior no âmbito europeu. Roldão destacou aspectos que nos aproximam e que, ao mesmo tempo, nos distanciam das políticas nessa área, as quais destacamos as conquistas das últimas décadas no âmbito do direito à educação pelas crianças pequenas no Brasil, o que não foi acompanhado por um processo de efetiva qualidade (a exemplo do que ocorreu com outros níveis e modalidades educacionais). A centralidade da formação prática e profissionalizante e da articulação entre teoria e prática assinaladas por Roldão nos cursos de formação de professores em Portugal, nos ajuda a refletir sobre o caráter generalista dos cursos de Pedagogia, a dificuldade de existência de organizações curriculares integradoras e de trabalho coletivo com os professores desses cursos no Brasil, o compromisso com o perfil do egresso a ser formado, além da necessária relação das instituições formadoras de professores com as escolas de educação básica.

Essa reflexão contribui, de maneira efetiva e contextualizada, para se pensar a formação do professor polivalente para a educação infantil e também para os anos iniciais do ensino fundamental, pelo fato de que a maioria dos professores na realidade brasileira é formada por instituições de ensino superior privadas (e não universitárias) que não têm a tradição de atuação em pesquisas, o que prejudica a dimensão da investigação na formação desses profissionais. Outro aspecto revelado pela entrevistada e que incide diretamente sobre a qualidade dos professores é a avaliação externa dos cursos de formação de professores que conta, no caso de Portugal, com autonomia, e que é levada a efeito por uma agência independente das ações do Ministério da Educação. Tal condição nos parece indispensável e necessária no Brasil, um país que tenta universalizar a educação básica (com oferta e com qualidade), que conta ainda com infindáveis desafios e que apresenta frágil condição democrática e de garantia de direitos sociais.

\section{REFERÊNCIAS}

ROLDÃO, M.C. Considerações finais: questões emergentes. In MACHADO, E.; COSTA, N.; ALVES, P. (Orgs.). Avaliação do desempenho docente: compreender a complexidade, sustentar a decisão. Santo Tirso: De Facto Editores; Universidade de Aveiro, 2013. p.167-182. 